\title{
Classification of CryoSat-2 radar echoes
}

\author{
Robert Ricker, Stefan Hendricks, Veit Helm, Rüdiger Gerdes
}

\begin{abstract}
Sea-ice thickness at global scale is an important variable in the polar climate system. Only satellite altimeters such as onboard the CryoSat- 2 mission allow us to obtain sea-ice thickness on hemispherical scale. Accurate CryoSat-2 altimeter range measurements provide surface elevations which have to be referenced to the local sea level to obtain sea-ice freeboard that can be converted into sea-ice thickness assuming hydrostatic equilibrium. The local sea-surface height is determined by careful detection of leads in the ice surface using the specific characteristics of the radar signal. Off-nadir reflections from leads can significantly affect the range retracking and hence bias the surface elevations of leads and sea ice. This can finally lead to a negative freeboard and hence also affects the thickness and volume retrieval. We present a method for the classification of CryoSat-2 radar echoes to correctly discriminate between valid and off-nadir biased echoes. We apply our classification to a CryoSat-2 track from December 15 where 50 leads over a distance of $2300 \mathrm{~km}$ are identified. Overall $22 \%$ of the surface elevations are associated with biased radar echoes.
\end{abstract}

Robert Ricker

Alfred Wegener Institute, Helmholtz Centre for Polar and Marine Research, Bussestrasse 24, 27570

Bremerhaven, Germany, e-mail: Robert.Ricker@awi.de

Stefan Hendricks

Alfred Wegener Institute, Helmholtz Centre for Polar and Marine Research, Bussestrasse 24, 27570

Bremerhaven, Germany, e-mail: Stefan.Hendricks@awi.de

Veit Helm

Alfred Wegener Institute, Helmholtz Centre for Polar and Marine Research, Am Alten Hafen 26, 27568 Bremerhaven, Germany, e-mail: Veit.Helm@awi.de

Rüdiger Gerdes

Alfred Wegener Institute, Helmholtz Centre for Polar and Marine Research, Bussestrasse 24, 27570

Bremerhaven, Germany, e-mail: Ruediger.Gerdes@awi.de 

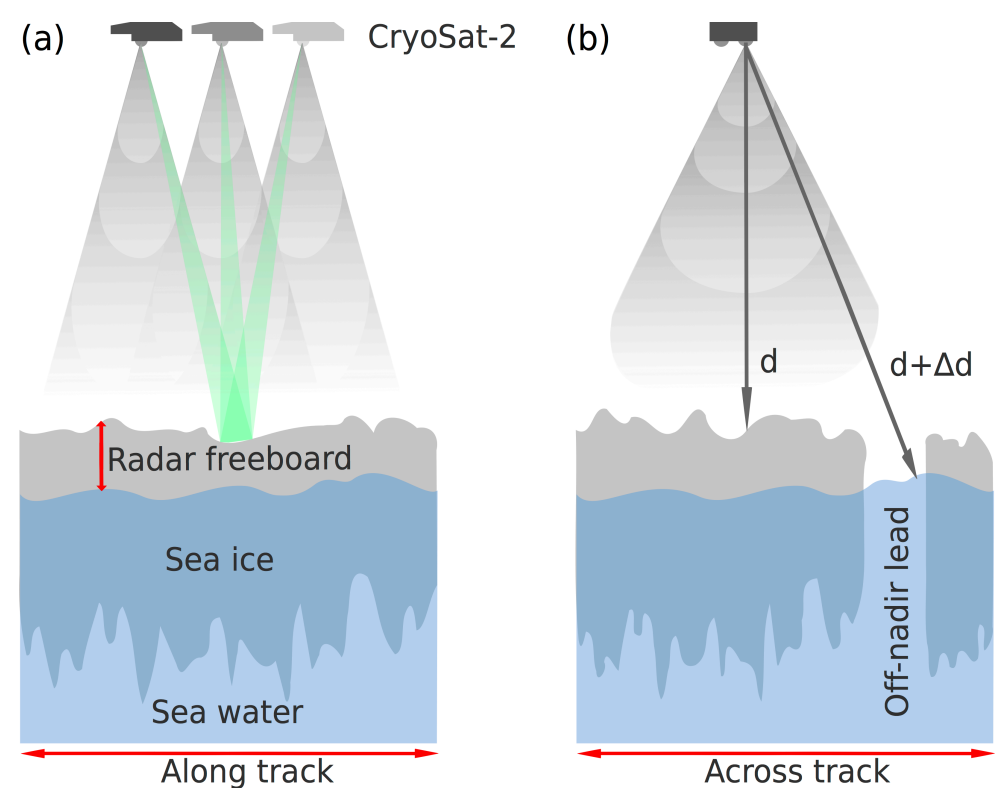

Fig. 1 (a) Scheme of CryoSat-2 measurements along track. The green illuminated area illustrates a Doppler cell. (b) Scheme of CryoSat-2 measurement across track with an off-nadir lead at the edge of the main radar lobe, causing a range bias of $\Delta \mathrm{d}$.

\section{Introduction}

Several studies have shown considerable evidence that the Arctic sea ice is thinning during the last decades $[13,9,6]$. When combined with the observed rapid reduction of the ice covered area $[2,3,14]$ this leads to a decline in sea-ice volume [10]. The only remote sensing technique capable of quantifying this ice-volume decrease at global scale is satellite altimetry. This method is based on the retrieval of the seaice freeboard, which is the height of the ice-surface above the local sea level (Fig. 1a). Assuming hydrostatic equilibrium the freeboard can be converted into sea-ice thickness $[15,5,9]$ and with additional information into sea-ice volume [10].

Satellite altimeters are operated in different electromagnetic wavelength ranges. The laser altimeter onboard the ICESat mission featured a small footprint $(70 \mathrm{~m})$ but was affected by clouds. Radar altimeters on the other hand are not affected by clouds but have a larger footprint of several kilometres. CryoSat-2 is the current satellite altimeter mission of the European Space Agency (ESA) and was launched in April 2010, with special emphasis on Arctic sea ice. It is equipped with a Ku-Band SAR radar altimeter (SIRAL - Synthetic Aperture Interferometric Radar Altimeter) that uses along-track beam sharpening [16] to reduce footprint size compared to previous radar altimeter missions (ERS1/2, Envisat). By using the effect of the Doppler shift the radar footprint can be divided into stripes called Doppler cells (for CryoSat-2 approximately $250 \mathrm{~m}$ ). Each cell is illuminated from different incident angles as the 

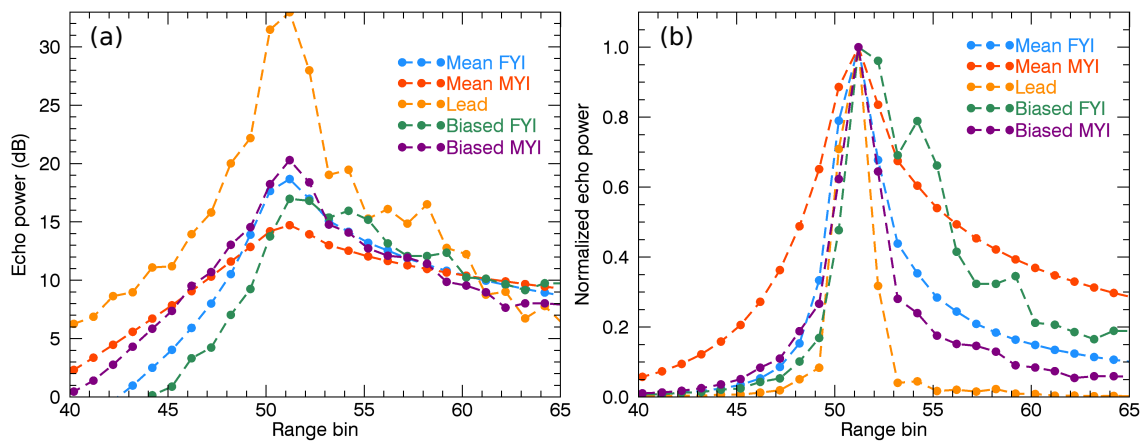

Fig. 2 CryoSat-2 waveforms from different surface types for the CryoSat-2 ground track in Fig. 3. The mean first-year ice (FYI) and multi-year ice (MYI) waveforms are an average of all FYI (MYI) waveforms along the track. (a) shows all waveforms aligned to the peak power in $\mathrm{dB}$. (b) shows all waveforms normalized and aligned to the peak power.

satellite passes by (Fig. 1a). The echoes of each illumination are stacked to reduce noise. This method results in a higher resolution than pulse-limited radar altimeters like onboard ERS1/2 and Envisat.

Since the uncertainties of freeboard can easily reach the magnitude of freeboard itself, optimized algorithms that reduce errors and uncertainties in CryoSat-2 freeboard retrieval are necessary. The first step in obtaining sea-ice freeboard is to determine the main scattering horizon to receive geolocated surface elevations $[8,12]$. In this study a threshold first-maximum retracker with a $40 \%$ threshold (TFMRA40) $[12,7]$ is applied to the geolocated radar echoes (waveforms) that are provided by the European Space Agency. Within this retracker algorithm the waveform is oversampled and smoothed. We compute the derivative to find the first maximum of the waveform and assign the main scattering horizon at $40 \%$ of this first peak. The effects of different thresholds and retrackers on the freeboard retrieval can be substantial and have been investigated in [12] and [8]. In the second step the geolocated CryoSat-2 elevations have to be referenced to the sea level to obtain the freeboard. We apply a waveform classification algorithm [12] in order to detect leads which are narrow open water areas in the ice surface. At leads the sea level can directly be obtained by the CryoSat-2 range measurement. The lead elevations are interpolated along the CryoSat-2 ground tracks to receive the actual sea-surface height which is then subtracted from the sea-ice elevations to get the sea-ice freeboard.

[1] have shown that off-nadir reflections from leads can bias the range retrieval since elevation retrievals are based on the assumption that the main reflector is in the nadir of the satellite. They typically occur when specular reflection on the edge of the main radar lobe still dominate the return signal (Fig. $1 \mathrm{~b}$ and 2 ). These biased waveforms are mostly a composition of reflections of leads and sea ice. They can potentially affect elevations of leads if classified as leads as well as ice elevations if classified as sea ice and cause a range bias of $\Delta \mathrm{d}$ (Fig. 1b). In this study we present our method to discriminate waveforms that are biased by off-nadir reflections from 
leads and valid sea-surface height information. In addition the waveform classification scheme is extended to also discriminate different ice types.

\section{Methods}

Before referencing the ice elevations to the local sea level we have to assign waveforms to surface types. In this study we only focus on sea-ice and lead waveforms. Leads show an almost specular reflection due to the absence of surface waves in ice covered areas, because the surface of narrow open water areas is usually smooth. In contrast, reflections from sea ice have diffuse characteristics. Hence the echo power of a lead waveform is significantly higher than for a radar return from sea ice (Fig. 2a). Radar returns from the open ocean can be also considered as tie points for the sea surface height but are less relevant in referencing the ice elevations because this surface type mostly occurs in the marginal ice zone. Ocean waveforms are highly affected by waves and have different characteristics.

We here use the findings of [17] and [12] and use different waveform characteristics to discriminate between first-year ice (FYI) and multi-year ice (MYI). The pulse peakiness PP is described in [11] and indicates the shape of the power distribution of the waveform. Since waveforms from leads show specular returns, their PP is higher than those for sea ice with the waveform widened by diffuse reflections. The echo power contribution of an off-nadir lead is registered after the return from the nadir area but is of specular nature. Thus the retracker algorithm will fix the main scattering horizon at the leading edge of the lead. In order to identify those biased waveforms we introduce a left- and right-peakiness $\mathrm{PP}_{1}$ and $\mathrm{PP}_{\mathrm{r}}[12]$. They are defined as:

$$
\begin{aligned}
\mathrm{PP}_{\mathrm{r}} & =\frac{\max (\mathrm{WF})}{\operatorname{mean}\left(\left[\mathrm{WF}_{\mathrm{i}_{\text {max }}-3}, \mathrm{WF}_{\mathrm{i}_{\text {max }}-1}\right]\right)} \cdot 3 \\
\mathrm{PP}_{1} & =\frac{\max (\mathrm{WF})}{\operatorname{mean}\left(\left[\mathrm{WF}_{\mathrm{i}_{\text {max }}+1}, \mathrm{WF}_{\left.\left.\mathrm{i}_{\text {max }}+3\right]\right)}\right]\right.} \cdot 3
\end{aligned}
$$

where $\mathrm{WF}_{\mathrm{i}}$ is the echo power at range bin $\mathrm{i}$ and $\max (\mathrm{WF})$ the peak power of the waveform. $\mathrm{PP}_{1}$ and $\mathrm{PP}_{\mathrm{r}}$ are a measure for the peakiness left and right of the power maximum as we consider the ratio of the maximum power to the mean power of

only three range bins left and right of the maximum. In the case of a nadir lead the waveform power distribution is narrow and shows a high maximum echo power as well as high $\mathrm{PP}_{\mathrm{r}}$ and $\mathrm{PP}_{1}$ values (Fig. 2a and b).

For the lead identification we further use the parameter stack kurtosis (K), also a measure of peakiness [16], and the stack standard deviation (SSD), which is a measure of the variation in surface backscatter depending on the incident angle [16]. The term stack refers to the multi-look SAR processing [16]. Leads are associated with a high $\mathrm{K}$ and a low SSD because of their specular reflection. Table 1 shows a set of waveform parameters used for the discrimination between sea ice and leads. The 
Table 1 Waveform parameter and ice concentration thresholds used in the CryoSat-2 processing to identify the surface types Lead and multi-year (MYI) and first-year ice (FYI): pulse peakiness $\mathrm{PP}$, stack kurtosis $\mathrm{K}$, stack standard deviation $\mathrm{SSD}$, peakiness $\mathrm{PP}_{1}$ left of the power maximum, peakiness $\mathrm{PP}_{\mathrm{r}}$ right of the power maximum and sea-ice concentration IC.

\begin{tabular}{r|llllll}
\hline Surface type & $\mathrm{PP}$ & $\mathrm{K}$ & $\mathrm{SSD}$ & $\mathrm{PP}_{1}$ & $\mathrm{PP}_{\mathrm{r}}$ & $\mathrm{IC}(\%)$ \\
\hline Lead & $\geq 40$ & $\geq 40$ & $\leq 4$ & $\geq 40$ & $\geq 30$ & $\geq 70$ \\
Sea ice (FYI) & & & & $\leq 60$ & $\leq 25$ & $\geq 70$ \\
Sea ice (MYI) & & & & $\leq 18$ & $\leq 15$ & $\geq 70$ \\
\hline
\end{tabular}

threshold values were determined by test-processing of CryoSat- 2 ground tracks. All waveforms that do not comply with these constraints are discarded.

After the identification of leads, the actual sea level can be interpolated and subtracted from the CryoSat-2 elevations that were identified as sea ice. As a result we receive the radar freeboard according to [12].

\section{Results}

Here we show exemplary results from a CryoSat-2 ground track from December 15 . The track is directed south-east and first passes the MYI region north of Greenland before it passes over FYI in the marginal ice zone in the Fram Strait (Fig. 3). For the ice-type discrimination we use the OSI SAF ice-type product [4].

Fig. 4a reveals the range retrieval after subtracting the mean sea-surface height. Applying the waveform discrimination according to Table 1 we find 50 leads over a distance of $2300 \mathrm{~km}$. Radar echoes with waveform parameters that do not comply with the thresholds in Table 1 were discarded. Overall $22 \%$ of the FYI and $21 \%$ of the MYI waveforms are discarded. The fraction of detected leads is $0.7 \%$ for FYI and $0.5 \%$ for MYI. The difference of waveform characteristics between FYI and MYI can be seen in the fact that if we use the MYI thresholds for FYI we discard $86 \%$ of the FYI waveforms.

Fig. $4 \mathrm{~b}$ shows the left- and right-peakiness along the CryoSat-2 track. Within the MYI the left-peakiness reveals a mean value of 9.0 (Table 2) whereas for FYI we find a mean $\mathrm{PP}_{1}$ of 32.0. Furthermore the scattering for FYI is higher than for MYI. The right-peakiness $\mathrm{PP}_{\mathrm{r}}$ shows overall less scattering compared to $\mathrm{PP}_{1}$. It reveals mean values of 5.6 for MYI and 10.1 for FYI. The mean difference between FYI and MYI is lower than for $\mathrm{PP}_{1}$ but also shows higher values for FYI (Table 2). In coincidence with negative outliers in the MYI zone in Fig. 4a we find increased values for $\mathrm{PP}_{\mathrm{r}}$ and $\mathrm{PP}_{1}$.

Considering the biased waveforms in Table 2 we find $\mathrm{PP}_{1}$ values of 21.5 for FYI and 38.7 for MYI. These values are significantly higher than the mean value for MYI, but in the range of the mean $\mathrm{PP}_{1}$ for FYI. On the other hand, the $\mathrm{PP}_{\mathrm{r}}$ for MYI is close to the mean $\mathrm{PP}_{\mathrm{r}}$ of the unbiased MYI waveforms. 

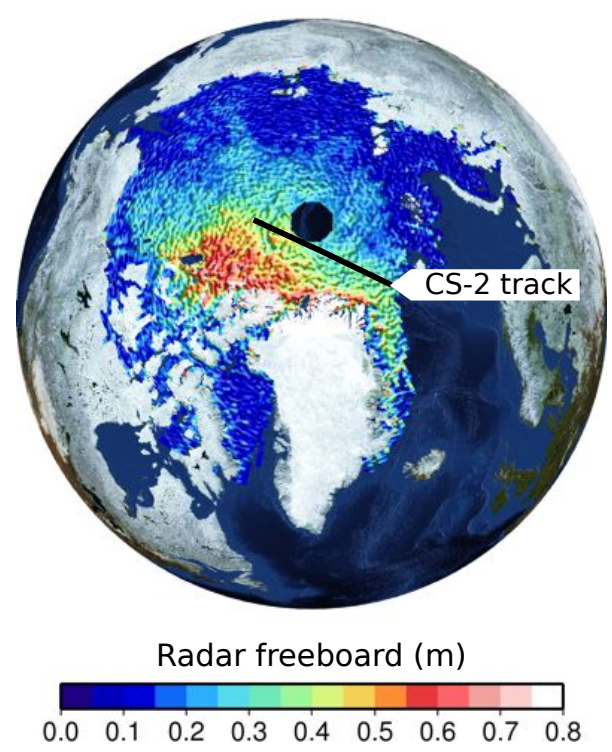

Fig. 3 CryoSat-2 monthly mean radar freeboard from December 2013, using a $40 \%$ retracker threshold. The black line shows the CryoSat- 2 ground track that is considered in this study.

\section{Discussion}

Waveforms from FYI and MYI are of significantly different nature, which has been already investigated in [17]. Surface properties of MYI, involving snow cover and surface roughness, cause a shallow echo power distribution in the waveform whereas for FYI we find a steeper leading edge (Fig. 2) which results in increased left- and right peakiness values (Fig. 4b).

This finding has direct consequences for the classification of off-nadir reflections from leads that can either bias the interpolation of the sea-surface, if classified as leads, or affect the surface elevations of the sea ice, if classified as sea ice. In the first case high thresholds for the peakiness are necessary to exclude off-nadir leads. In the second case off-nadir leads cause decreased ice elevations which is shown in Fig. 4a for example between 200 and $400 \mathrm{~km}$. In the FYI zone, we do not observe a similar effect. Fig 2 shows biased waveforms of FYI and MYI. Both are a composition of an off-nadir lead reflection and reflections from sea ice. The biased MYI waveform shows a high left-peakiness of 38.7 while the right-peakiness is 5.2 which is close to the value for mean MYI. Here the off-nadir lead seems to dominate the peak power. Thus the waveform is dominated by the off-nadir lead reflection and the range is tracked at the leading edge of the lead waveform contribution, resulting in a range bias $\Delta \mathrm{d}$ (Fig. 1b). Considering $\mathrm{PP}_{1}$ and $\mathrm{PP}_{\mathrm{r}}$ allows us to characterize waveforms and to identify biased waveforms. 
Table 2 Values of left-peakiness $\left(\mathrm{PP}_{1}\right)$ and right-peakiness $\left(\mathrm{PP}_{\mathrm{r}}\right)$ for the different surface types that are shown in Fig. 2 .

\begin{tabular}{r|rrrrr}
\hline Waveform parameter & Mean FYI & Mean MYI & Lead & Biased FYI & Biased MYI \\
\hline $\mathrm{PP}_{1}$ & 32.0 & 9.0 & 87.2 & 21.5 & 38.7 \\
$\mathrm{PP}_{\mathrm{r}}$ & 10.1 & 5.6 & 109.0 & 15.1 & 5.2 \\
\hline
\end{tabular}

FYI waveforms can exhibit similar shapes and properties as biased MYI. As a consequence, FYI waveforms might be discarded if they are classified as MYI in the OSI SAF ice type.

We also note that for FYI we find fewer outliers than for MYI (Fig. 4a ). We can speculate that the backscatter from FYI is usually higher than from MYI (Fig.2a). An off-nadir lead reflection is then in certain cases still distinguishable from the sea-ice echo as shown in Fig. 2 (green line). We can identify two peaks where the first represents the sea-ice reflection and the second the off-nadir lead that is well separated from the ice waveform. Therefore the retracker algorithm captures the leading edge of the sea-ice echo correctly and hence a range bias does not occur. Therefore we can use higher thresholds of $\mathrm{PP}_{1}$ and $\mathrm{PP}_{\mathrm{r}}$ for FYI than for MYI to avoid discarding FYI waveforms erroneously. However, another reason for fewer outliers in the FYI zone could be a different pattern and distribution of leads in the considered FYI area.

The uncertainties of the range retrieval are discussed in more detail in [12]. Besides a bias due to the choice of the retracker, the uncertainty is dominated by the speckle noise $[16,10]$ that is around $0.1 \mathrm{~m}$ for a single measurement. Using the OSI SAF ice-type product for the waveform classification also induces a classification uncertainty [4] and might lead to an underrepresentation of FYI within the MYI zone. Therefore a combined ice-type classification using the CryoSat-2 waveforms as well as the OSI SAF ice-type product might be a reasonable approach for the future. The thresholds in Table 1 for FYI and MYI are empirical and where chosen considering the distribution of $\mathrm{PP}_{1}$ and $\mathrm{PP}_{\mathrm{r}}$ in Fig. 4b. Valid outliers in Fig. 4a could not be identified as biased waveforms and still affect the freeboard retrieval.

\section{Conclusion}

In this study we present a method to classify CryoSat-2 waveforms using a combination of parameters that characterize the radar echo. We use a left- and rightpeakiness to characterize surface types and to identify waveforms that are biased by off-nadir-leads. Those waveforms can cause a decrease in surface elevation, especially for multi-year ice while for first-year ice this bias does not have a significant effect. Therefore we used higher threshold values for the left- and right-peakiness for first-year ice to avoid discarding first-year ice waveforms erroneously. Overall 

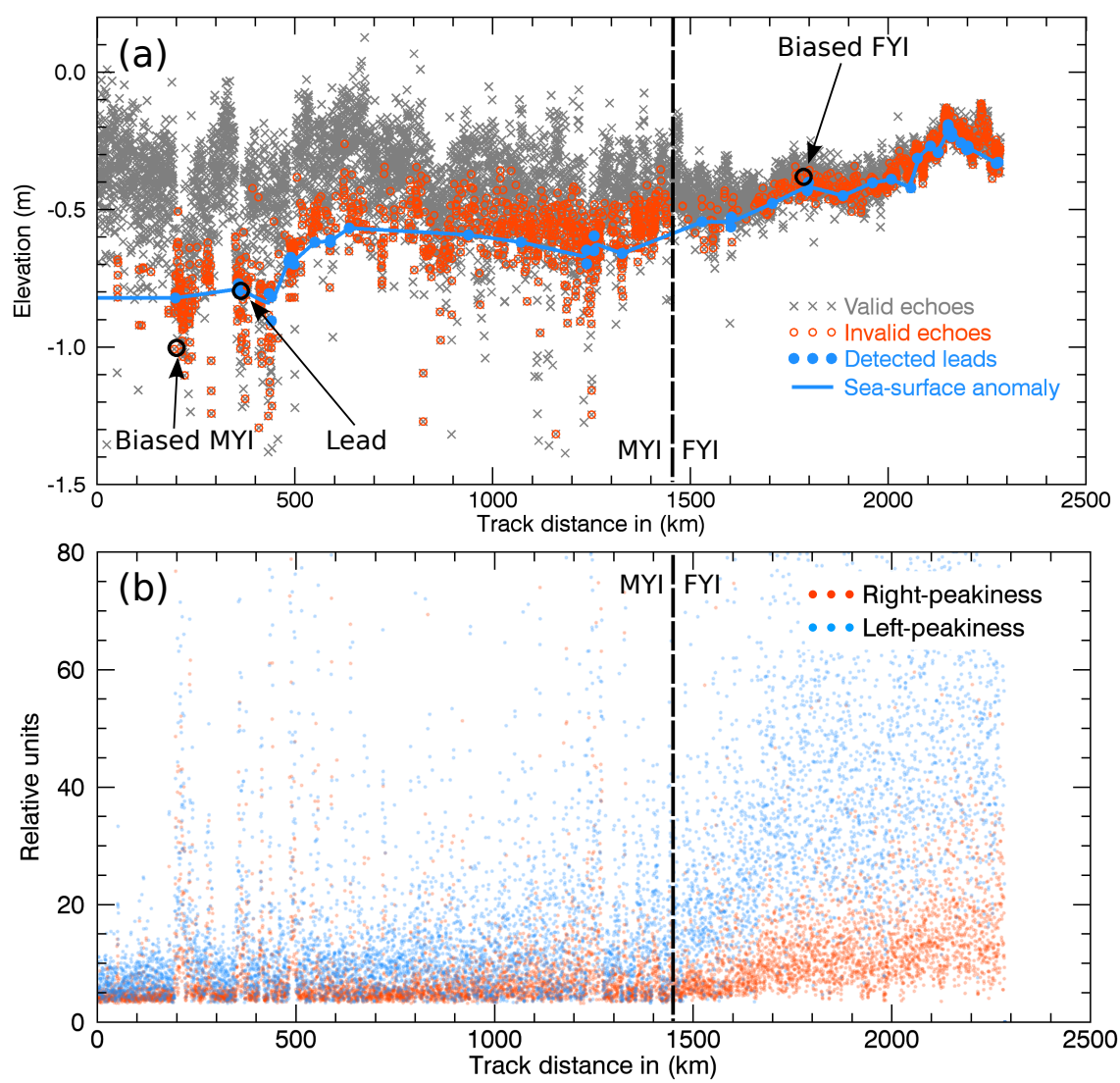

Fig. 4 a) Geolocated CryoSat-2 surface elevations after retracking with a $40 \%$ threshold and subtraction of the mean sea-surface height which has been interpolated along the CryoSat- 2 ground track. Highlighted points belong to the waveforms in Fig. 2. (b) Right- and left-peakiness along the CryoSat- 2 ground track. The dashed vertical line marks the boundary between first- and multi-year ice.

we discarded $22 \%$ of the radar echoes of a CryoSat- 2 ground track from December 15, 2013. Using the multi-year ice thresholds of left- and right-peakiness for FYI would lead to a rejection of $86 \%$ of the first-year ice waveforms because the shape of first-year ice waveforms is similar to invalid waveforms from multi-year ice that are biased by off-nadir leads. However, since we rely on the OSI SAF ice-type product valid first-year might be underrepresented if indicated as multi-year ice.

Acknowledgements We thank the European Space Agency for providing the CryoSat-2 data. We further thank the Earth-System Science Research-School (ESSRES) for any support during this Phd project. The work of S. Hendricks and V. Helm was funded by the 268 Federal Ministry of Economics and Technology (Grant 50EE1008). For the usage of images of The Blue Marble: Next Generation we thank NASAs Earth Observatory. 


\section{References}

1. Armitage, T., Davidson, M.: Using the interferometric capabilities of the esa cryosat- 2 mission to improve the accuracy of sea ice freeboard retrievals. Geoscience and Remote Sensing, IEEE Transactions on 52(1), 529-536 (2014). DOI 10.1109/TGRS.2013.2242082

2. Comiso, J.C.: A rapidly declining perennial sea ice cover in the arctic. Geophys. Res. Lett. 29(20) (2002). DOI 10.1029/2002GL015650. URL http://dx.doi.org/10.1029/2002GL015650

3. Comiso, J.C., Parkinson, C.L., Gersten, R., Stock, L.: Accelerated decline in the Arctic sea ice cover. Geophysical Research Letters 35(L01703) (2008). URL http://www.agu.org/pubs/crossref/2008/2007GL031972.shtml

4. Eastwood, S.: OSI SAF Sea Ice Product Manual, v3.8 edn. (2012). URL http://osisaf.met.no

5. Giles, K.A., Laxon, S.W., Ridout, A.L.: Circumpolar thinning of arctic sea ice following the 2007 record ice extent minimum. Geophysical Research Letters 35(22), L22,502 (2008). DOI 10.1029/2008GL035710. URL http://dx.doi.org/10.1029/2008GL035710

6. Haas, C., Hendricks, S., Eicken, H., Herber, A.: Synoptic airborne thickness surveys reveal state of arctic sea ice cover. Geophysical Research Letters 37(9), L09,501 (2010). DOI 10.1029/2010GL042652. URL http://dx.doi.org/10.1029/2010GL042652

7. Helm, V., Humbert, A., Miller, H.: Elevation and elevation change of greenland and antarctica derived from cryosat-2. The Cryosphere 8(4), 1539-1559 (2014). DOI 10.5194/tc-8-15392014. URL http://www.the-cryosphere.net/8/1539/2014/

8. Kurtz, N.T., Galin, N., Studinger, M.: An improved cryosat-2 sea ice freeboard and thickness retrieval algorithm through the use of waveform fitting. The Cryosphere Discussions 8(1), 721-768 (2014). DOI 10.5194/tcd-8-721-2014. URL http://www.the-cryospherediscuss.net/8/721/2014/

9. Kwok, R., Cunningham, G.F., Wensnahan, M., Rigor, I., Zwally, H.J., Yi, D.: Thinning and volume loss of the arctic ocean sea ice cover: 2003-2008. J. Geophys. Res. 114(C7) (2009). DOI 10.1029/2009JC005312

10. Laxon, S.W., Giles, K.A., Ridout, A.L., Wingham, D.J., Willatt, R., Cullen, R., Kwok, R., Schweiger, A., Zhang, J., Haas, C., Hendricks, S., Krishfield, R., Kurtz, N., Farrell, S., Davidson, M.: Cryosat-2 estimates of arctic sea ice thickness and volume. Geophysical Research Letters 40(4), 732-737 (2013). DOI 10.1002/grl.50193. URL http://dx.doi.org/10.1002/grl.50193

11. Peacock, N.R., Laxon, S.W.: Sea surface height determination in the arctic ocean from ers altimetry. Journal of Geophysical Research: Oceans 109(C7), C07,001 (2004). DOI 10.1029/2001JC001026. URL http://dx.doi.org/10.1029/2001JC001026

12. Ricker, R., Hendricks, S., Helm, V., Skourup, H., Davidson, M.: Sensitivity of cryosat2 arctic sea-ice freeboard and thickness on radar-waveform interpretation. The Cryosphere 8(4), 1607-1622 (2014). DOI 10.5194/tc-8-1607-2014. URL http://www.thecryosphere.net/8/1607/2014/

13. Rothrock, D.A., Yu, Y., Maykut, G.A.: Thinning of the arctic sea-ice cover. Geophys. Res. Lett. 26(23), 3469-3472 (1999). DOI 10.1029/1999GL010863

14. Stroeve, J., Serreze, M., Holland, M., Kay, J., Malanik, J., Barrett, A.: The arctic's rapidly shrinking sea ice cover: a research synthesis. Climatic Change 110(3-4), 1005-1027 (2012). DOI 10.1007/s10584-011-0101-1. URL http://dx.doi.org/10.1007/s10584-011-0101-1

15. Wadhams, P., Tucker W. B., I., Krabill, W.B., Swift, R.N., Comiso, J.C., Davis, N.R.: Relationship between sea ice freeboard and draft in the arctic basin, and implications for ice thickness monitoring. J. Geophys. Res. 97(C12), 20,325-20,334 (1992). DOI 10.1029/92JC02014

16. Wingham, D., Francis, C., Baker, S., Bouzinac, C., Brockley, D., Cullen, R., de ChateauThierry, P., Laxon, S., Mallow, U., Mavrocordatos, C., Phalippou, L., Ratier, G., Rey, L., Rostan, F., Viau, P., Wallis, D.: Cryosat: A mission to determine the fluctuations in earth's land and marine ice fields. Advances in Space Research 37(4), 841 - 871 (2006). DOI 10.1016/j.asr.2005.07.027

17. Zygmuntowska, M., Khvorostovsky, K., Helm, V., Sandven, S.: Waveform classification of airborne synthetic aperture radar altimeter over arctic sea ice. The Cryosphere 7(4), 1315-1324 (2013). DOI 10.5194/tc-7-1315-2013. URL http://www.the-cryosphere.net/7/1315/2013/ 